\title{
Sistemas de cuidados e o discurso de diferentes cuidadores do Rio de Janeiro: evidências de trajetória de desenvolvimento
}

\section{Child care systems and discourse of different caretakers}

\author{
in Rio de Janeiro, Brazil: Evidences
}

of development trajectories

\author{
Luciana Fontes PESSÔA \\ Maria Lucia SEIDL-DE-MOURA ${ }^{2}$ \\ Dandara de Oliveira RAMOS ${ }^{3}$ \\ Deise Maria Leal Fernandes MENDES ${ }^{2}$
}

\begin{abstract}
Resumo
Contemporaneamente, o cuidado de crianças pequenas em sociedades urbanas e ocidentais tem sido compartilhado, principalmente em famílias de nível socioeconômico médio, com creches, babás ou avós maternas. Quando se pensa no desenvolvimento no contexto e nas trajetórias que assume, é necessário considerar as crenças desses diferentes cuidadores. Assim, a exploração das trajetórias de desenvolvimento evidenciadas no discurso dos diferentes cuidadores na construção do self de crianças em um contexto do Rio de Janeiro pode ser enriquecedora. Uma entrevista semiestruturada, utilizando cinco fotos que retratavam os cinco Sistemas de Cuidados Parentais, foi realizada em 60 duplas constituídas por mães com filhos de até um ano, avós, babás e educadoras de creche. Os sistemas mais valorizados pelas participantes foram "contato corporal" e "face-a-face". Características desse discurso são discutidas em relação às crenças dos cuidadores e às tendências de trajetórias de desenvolvimento priorizadas.
\end{abstract}

Palavras-chave: Cuidado da criança; Cuidado parental; Cuidadores; Desenvolvimento infantil.

\begin{abstract}
The care of young children in urban and Western societies has currently been shared, especially between daycare services, nannies, and maternal grandmothers, mainly in middle-class families. When considering the developmental process and its trajectories in the context studied, it is necessary to take the beliefs of these different caregivers into consideration. Therefore, studying and understanding the development trajectories in the children's construction of

$\checkmark \nabla \nabla$

1 Pontifícia Universidade Católica do Rio de Janeiro, Departamento de Psicologia, Programa de Pós-Graduação em Psicologia Clínica. R. Marquês de São Vicente, 225, Sala 201, Edifício Cardeal Leme, 22451-900, Rio de Janeiro, RJ, Brasil. Correspondência para/Correspondence to: L.F. PESSÔA. E-mail: <pessoalf@gmail.com>.

2 Universidade do Estado do Rio de Janeiro, Instituto de Psicologia, Programa de Pós-Graduação em Psicologia Social. Rio de Janeiro, RJ, Brasil.

${ }^{3}$ Universidade do Estado do Rio de Janeiro, Faculdade de Ciências Médicas, Instituto de Medicina Social. Rio de Janeiro, RJ, Brasil.
\end{abstract}


self that are evident in the discourse of different caregivers in the city of Rio de Janeiro, Brazil, is important. A semi-structured interview using five photographs representing different Parental Care Systems was conducted with a total of 60 dyads composed of mothers of children up to one year old and a child care provider: grandmothers, nannies, and daycare educators, 20 dyads of each, respectively. Body contact and face-to-face contact were the most frequent mentioned discourse of the respondents. The characteristics of these discourses are discussed in terms of their beliefs and the tendencies of development trajectories prioritized.

Keywords: Child care; Parental care; Caregivers; Child development.

Uma das principais características das famílias contemporâneas em contextos urbanos é a divisão, cada vez mais equilibrada, entre mulheres e homens no sustento da casa. Estudos recentes mostram uma tendência crescente da participação feminina, da classe média e das regiões urbanas, no mercado de trabalho, com jornadas extensas que requerem esforços redobrados quando associadas ao exercício da maternidade (Cohen \& Bianchi, 1999; Crosby \& Hawkes, 2007; Hansen \& Hawkes, 2009).

Como consequência disso, o cuidado de bebês e crianças pequenas vem sendo compartilhado com diferentes personagens: avós, babás e educadoras de creches passam a figurar o cenário dos cuidados iniciais, tradicionalmente centrado na figura da mãe. A presença de outros cuidadores/ educadores faz refletir sobre as possíveis influências dessas pessoas no desenvolvimento do self das crianças. Nesse novo panorama, desde as etapas iniciais do desenvolvimento, as crianças estarão em contato com crenças, valores e comportamentos não necessariamente semelhantes ou convergentes com os de sua principal cuidadora, a mãe.

É pressuposto deste trabalho que o desenvolvimento do self acontece a partir de um quadro de possíveis e diferentes alternativas de trajetórias de socialização, das quais destacam-se as que priorizam a autonomia e/ou a interdependência. Essas dimensões do self fazem parte do contexto de sistemas de cuidados parentais, segundo o modelo proposto por Keller (2007), os quais se organizam de formas variadas. Neste estudo, buscou-se identificar quais sistemas são privilegiados pelos diferentes perfis de cuidadores e analisar categorias específicas da fala dos mesmos que estivessem relacionadas aos sistemas de cuidados parentais. O principal objetivo foi identificar, a partir do discurso, as tendências de 72 trajetórias de desenvolvimento valorizadas.

\section{Trajetórias de socialização: autonomia e interdependência}

Bebês humanos precisam muito de suas mães. Crianças, até pelo menos o fim do primeiro ano, necessitam da presença materna por tempo quase que integral para seus cuidados e para seu desenvolvimento (Sear \& Mace, 2008). Os quatro meses de licença maternidade, atualmente concedidos pela legislação trabalhista no Brasil, não são suficientes frente ao período pelo qual são necessários os intensos e continuados cuidados maternos no início da vida. Com isso, outros cuidadores são introduzidos nas rotinas diárias para complementarem a atenção à grande demanda dos bebês. Com experiências e histórias de vida distintas, avós, babás e educadoras de creche tornam-se parte do processo de socialização dessas crianças, em um período crucial para o seu desenvolvimento.

De acordo com Keller e Chasiotis (2007), o tipo de investimento realizado pelos cuidadores estaria relacionado com as trajetórias de socialização que eles valorizam. Essas trajetórias podem ser voltadas para interdependência, que se caracteriza por perceber o indivíduo sempre como membro de um sistema social, tendo deveres e obrigações com o grupo ao qual pertence, ou voltadas para independência, com valorização do individualismo, da autonomia, da autorrealização e da autossuficiência (Bandeira \& Seidl-de-Moura, 2012). A primeira, segundo estudos de Keller (2007), é comum em sociedades rurais tradicionais de subsistência e a segunda predomina entre indivíduos urbanos de sociedades industriais. Além dessas duas orientações, Kagitçibasi (2007) propôs uma terceira, que se orienta para o desenvolvimento de um self autônomo-relacional, envolvendo características dos dois modelos. 
Segundo Kagitçibasi (2011), a urbanização mundial e a imigração têm consequências significativas para a teoria psicológica e, em suas argumentações teóricas, busca descrever como fatores socioculturais podem implicar no desenvolvimento humano. A autora aponta que os conceitos de autonomia e interdependência têm sido vistos como conflitantes, quando, na verdade, não seria lógico entendê-los desse modo. A existência de um não significa a falta do outro e, segundo ela, a importância e a ênfase que têm sido dadas à autonomia faz com que a interdependência seja negligenciada.

A construção do self, portanto, assim como a participação das dimensões de autonomia e interdependência nessa construção, são avaliadas como de grande importância teórica e empírica. Elas começam a ser elaboradas na infância em contextos específicos e, dependendo dele, autonomia e interdependência ganharão importâncias diferentes, mas sempre coexistirão já que os seres humanos precisam de ambas (Keller, 2011). Para a autora, as experiências sociais iniciais, organizadas por crenças e práticas dos cuidadores, tanto individuais como compartilhadas com o grupo, constituem as bases dessas trajetórias distintas.

Ainda de acordo com Keller (2011), nos dois primeiros anos de vida da criança, os cuidados recebidos e as interações com os cuidadores são organizadas de acordo com a predominância de diferentes sistemas parentais. Esses sistemas são universais e resultado de propensões para o cuidado em nossa espécie. A autora descreve seis sistemas parentais, os quais serão descritos a seguir.

O primeiro deles, o de "cuidados básicos", envolve as atividades de cuidados ao bebê, como dar banho, trocar fraldas, alimentar, proteger, entre outras. Esse sistema, além de ter a função de diminuir o estresse infantil, influencia diretamente o desenvolvimento, na criança, de um sentimento de segurança, proteção e confiança. Já no sistema de "contato corporal", as posições de contato entre cuidador e bebê prevalecem. Podem ser exemplificadas com as atividades de carregar o bebê junto ao corpo, no colo, nas costas ou no quadril. A principal função desse sistema é de proteção e afeta diretamente o desenvolvimento do vínculo entre a mãe e o bebê, bem como a coesão grupal. Esses aspectos são associados à aceitação de normas e valores da geração anterior, preparando o indivíduo para uma vida baseada em hierarquia e harmonia na família e no grupo social primário.

Há, também, o sistema de "estimulação corporal", o qual envolve atividades de estimulação motora, cinestésica, tátil e/ou do equilíbrio do bebê. Ele promove o desenvolvimento motor infantil e intensifica a percepção corporal da criança, podendo influenciar diretamente a descoberta da autoeficácia corporal em relação aos recursos do ambiente e a emergência de um self corporal. No que diz respeito ao de "estimulação por objetos", este ocorre quando a mãe utiliza objetos na tentativa de atrair a atenção do bebê. Sua principal função é a adaptação do bebê ao mundo de objetos e ao próprio ambiente no qual está inserido. Nesse sistema são estimulados o desenvolvimento cognitivo e do sentimento de autonomia pela promoção do desengajamento parcial do bebê da dependência de relações iniciais.

No sistema "face-a-face" a mãe ajusta o bebê de tal maneira que seus rostos fiquem próximos e, com isso, mantenham contato pelo olhar. O contato visual diádico e o uso da linguagem são as atividades características desse sistema e oferecem a experiência de percepção contingente ao bebê. Acredita-se que o desenvolvimento da independência e a autoeficácia infantil, que prevalecem em contextos onde a competição e o individualismo são determinantes da estrutura social, sejam promovidos por esse sistema. Finalmente, o sexto sistema é o "envelope narrativo", o qual consiste em toda a mediação simbólica em que o bebê é envolvido por meio da fala da mãe.

Para Keller (2007), a partir das interações diádicas e de acordo com a predominância desses sistemas parentais e de mecanismos interacionais, a aprendizagem que se baseia em programas genéticos abertos leva a experiências que conduzirão a uma concepção modal do self. Essa concepção equilibra as relações entre dimensões psicológicas de: segurança ("self seguro"), identificada no sistema de cuidados primários e nas respostas contingentes ao bebê nas situações de estresse; relação 
("self social"), baseada no sistema de contato corporal e no calor emocional que a criança tem oportunidade de vivenciar; consciência corporal ("self corporal"), ligada ao sistema de estimulação corporal e a individualidade a ele relacionada; e de individualidade ("self mental"), relacionada ao sistema de estimulação por objetos e no sistema face-a-face, com respostas contingentes para os sinais positivos do bebê e atenção exclusiva.

A partir dessas diferentes trajetórias, o desenvolvimento do self orienta-se para direções diversas: de self independente, onde a independência é priorizada e o relacionamento distal prevalece, enfatizando as trocas face-a-face e a estimulação por objetos; de self interdependente, que prioriza a heteronomia e a relação e enfatiza o contato e a estimulação corporal; ou de self autônomo-relacional, onde prevalece tanto a autonomia quanto a relação. Essas classificações são derivadas dos modelos diferenciados de contato/cuidado de pais frente a seus filhos (Keller, 2007). Segundo a autora, os ambientes culturais diferem quanto à ênfase na autonomia e na relação em resposta a demandas do contexto. Nesse sentido, além de estudos em contextos culturais considerados prototípicos (Keller, 2011), entende-se fundamental ampliar a gama de investigações em diferentes culturas, além das que contemplem variações intra-culturais. Alguns estudos brasileiros foram realizados com esse objetivo (e.g., Seidl-de-Moura, Carvalho, \& Vieira, 2013).

\section{A fala dos cuidadores e suas crenças indicando trajetórias do desenvolvimento do self}

No que tange à linguagem dos cuidadores, acredita-se que as suas diferentes formas de uso reflitam as crenças e valores dos adultos de uma cultura e trajetórias específicas de desenvolvimento do self promovidas por eles. Adultos falam com bebês e sobre eles e o que pensam sobre cuidar dos mesmos. A capacidade dos cuidadores de adaptarem sua fala com bebês e crianças pequenas parece fazer parte de uma bagagem de disposições da espécie. Assim como os bebês têm predispo- e tratar estímulos linguísticos (Pinker, 2002; Rochat, 2001), os adultos da espécie têm propensões para cuidados parentais (Keller, 2007) e uma capacidade intuitiva para esses cuidados (H. Papousek \& Papousek, 1991).

A criança nasce em um meio linguístico e com predisposições para desenvolver e usar a linguagem com seus coespecíficos. Ao mesmo tempo, os que com ela interagem fazem uso da linguagem com as características específicas do contexto em que vivem. Engajada em interações e envolvida nesse "manto linguístico", ela se desenvolve cognitiva, emocional e socialmente. Isso é o que Keller (2007) chama de envelope narrativo.

Porém, não são só as mães oferecem à criança esse envelope narrativo. O cuidado de crianças pequenas em famílias urbanas contemporâneas tem sido assumido, principalmente naquelas de nível socioeconômico médio, por creches, babás ou avós maternas (Rapoport \& Piccinini, 2004). São esses os cuidadores que compõem um dos subsistemas do nicho de desenvolvimento de que falam Harkness e Supper (1996): um sistema articulado de três subsistemas - o ambiente físico e social, as crenças e as práticas de cuidadores.

Nesse sentido, o nicho de desenvolvimento das crianças nesses contextos de cuidado vai incluir, necessariamente, as crenças e práticas de cuidadores além das da mãe. Estudos brasileiros com mães têm indicado que a trajetória de desenvolvimento que parece estar sendo mais privilegiada é a que valoriza tanto a autonomia quanto a proximidade emocional ou relação com as figuras significativas, ou seja, a de autonomia relacional (Seidl-de-Moura \& Mendes, 2012).

No entanto, não há evidência sobre as crenças de outros cuidadores, como as educadoras de creche, babás e avós. É possível que a tendência a uma trajetória de socialização para autonomia relacionada se confirme. No entanto, como os estudos revistos por Seidl-de-Moura et al. (2013) indicam a influência da escolaridade na dinâmica de valorização de autonomia e interdependência, há a necessidade de se investigar como essa dinâmica se manifesta em outros cuidadores. Dessa forma, como parte de um estudo mais amplo que investiga 
o desenvolvimento do self e a valorização da autonomia e da relação, visou-se identificar na fala de cuidadores sua valorização dos diferentes sistemas parentais e, com isso, as tendências de trajetórias de desenvolvimento privilegiadas por eles.

\section{Método}

\section{Participantes}

Foram estudadas 60 duplas de mulheres constituídas por mães, avós, babás e cuidadoras de creche (20 duplas de mães e avós; 20 de mães e babás; e 20 de mães e educadoras de creche) da cidade do Rio de Janeiro. As mães que participaram do estudo tinham bebês com até um ano de idade e de ambos os sexos (43,3\% meninos e $56,7 \%$ meninas). A Tabela 1 apresenta a distribuição da escolaridade das participantes por subgrupo. Observa-se que há diferenças de escolaridade entre os três grupos $\left(\chi^{2}{ }_{6}=64,37 ; p<0,05\right)$, com as mães apresentando níveis mais altos do que as demais cuidadoras. As educadoras de creche são as que mais se aproximam do nível educacional das mães.

\section{Instrumentos}

\section{Entrevista sobre os sistemas de cuidados parentais}

Consiste em entrevista semiestruturada onde cinco fotos, as quais retratam cinco dos Sistemas de Cuidados Parentais discutidos por Keller (2007), foram apresentadas às participantes. As fotos foram tiradas especialmente para o estudo e a mãe retratada consentiu em seu uso para a pesquisa e publicação. Preparadas as imagens, as mesmas foram submetidas a juízes para verificar se retratavam, consistentemente, os sistemas desejados, havendo total concordância.

As fotografias apresentavam uma mãe com seu bebê no ambiente natural de sua casa, sendo que uma apresentava a mãe dando banho em seu bebê (sistema de "cuidados básicos"), a outra mostrava a mãe abraçada com o bebê junto ao corpo ("contato corporal"), uma terceira apresentava a mãe massageando os pés do bebê enquanto este se encontra deitado na cama ("estimulação corporal"), a quarta um bebê, também deitado na cama, enquanto a mãe lhe mostrava um brinquedo ("estimulação por objetos") e a última fotografia mostrava um bebê nos braços da mãe com a face voltada para o seu rosto ("interação face-a-face"). O sistema "envelope narrativo" não foi incluído na entrevista por não possibilitar uma representação visual.

\section{Procedimentos}

Na entrevista, onde o áudio foi analisado posteriormente, pediu-se à cuidadora que avaliasse as fotos apresentadas e as colocasse em ordem de importância. Após essa ordenação, pediu-se que comentasse cada foto e a importância conferida.

A atribuição de escores a cada sistema foi em função da ordem de importância em que a

Tabela 1

Distribuição da idade e escolaridade das participantes por subgrupo (Mães, Avós, Babás e Educadoras de Creche). Rio de Janeiro (RJ), 2010

\begin{tabular}{|c|c|c|c|c|c|c|c|c|}
\hline \multirow{2}{*}{$\frac{\text { Variáveis }}{\text { Idade }}$} & \multicolumn{2}{|c|}{ Mães $(n=60)$} & \multicolumn{2}{|c|}{ Avós $(n=20)$} & \multicolumn{2}{|c|}{ Babás $(n=20)$} & \multicolumn{2}{|c|}{$E C(n=20)$} \\
\hline & M & $D P$ & $M$ & $D P$ & $M$ & $D P$ & $M$ & $D P$ \\
\hline & 31,9 & 4,5 & 58,7 & 5,5 & 41,5 & 12,3 & 35,5 & 9,8 \\
\hline Escolaridade & $n$ & $\%$ & $\mathrm{n}$ & $\%$ & $n$ & $\%$ & $\mathrm{n}$ & $\%$ \\
\hline Até médio incompleto & 3 & 5 & 6 & 30 & 14 & 70 & 1 & 5 \\
\hline Ensino médio completo & 6 & 10 & 4 & 20 & 5 & 25 & 10 & 50 \\
\hline Acima do superior incompleto & 51 & 84,9 & 10 & 50 & 1 & 5 & 9 & 45 \\
\hline
\end{tabular}

Nota: M: Média de Idade; DP: Desvio-Padrão; EC: Educadoras de Creche. 
participante colocava as fotos. Assim, a primeira imagem escolhida recebia valor cinco, a segunda recebia o valor quatro e assim por diante até a quinta foto, a qual recebia o valor um. Como cada imagem recebeu um valor por ordenação, os dados são de natureza ordinal, remetendo a testes não paramétricos para a tomada de decisão em relação às hipóteses de pesquisa (Field, 2009).

Neste trabalho foram discutidos os dados da parte da entrevista em que as participantes falavam sobre as fotos escolhidas. Análises de conteúdo das respostas das cuidadoras foram realizadas, visando identificar em seus discursos tendências para autonomia ou interdependência.

Assim, doze categorias foram extraídas a partir da análise das entrevistas: 1) Higiene e saúde: atender as necessidades básicas do bebê, levar o bebê ao médico, atentar para as pistas do bebê, dar banhos regulares, trocar as fraldas, alimentar o bebê, etc.; 2) Afeto: carinho, calor emocional, calor humano, vínculo mãe-bebê; 3) Função materna: obrigação de mãe, responsabilidade, presença da mãe; 4) Segurança/Atenção: dar conforto e passar segurança, proteção, ficar atenta ao bebê; 5) Brincadeira: importância da brincadeira para o desenvolvimento, estímulo para despertar o interesse do bebê para objetos; 6) Contato físico: proximidade, contato da mãe com o filho, abraço; 7) Reconhecimento: reconhecimento da mãe pelo bebê, reconhecimento mútuo, reconhecimento do bebê, mãe fazer o bebê reconhecê-la, reconhecimento de objetos; 8) Comunicação: desenvolvimento da linguagem, conversa, comunicação verbal/conversa; 9) Contato visual: troca de olhar, importância do olhar; 10) Propriocepção: a criança descobrir seu próprio corpo, nomear as partes do corpo para o bebê; 11) Exercício: desenvolvimento motor, massagem como exercício; 12) Estimulação por objeto: utilização de objetos nos exercícios de estimulação do bebê.

O procedimento adotado para avaliação de fidedignidade das categorias procurou seguir as práticas usuais em estudos nacionais e internacionais que se destacam pela preocupação com o rigor científico. Assim, como recomendado por
15 a $20 \%$ do material contendo as transcrições das repostas das participantes foi selecionado aleatoriamente e submetido a juízes para análise de fidedignidade das categorias.

Durante uma reunião com o pesquisador responsável pela pesquisa, três juízes independentes receberam um pequeno manual de instruções em que estavam descritas as categorias de análise, suas respectivas definições e os procedimentos que deveriam adotar em suas categorizações. Calculando-se a concordância entre observadores foi obtido um índice de concordância superior a 85\%. Além disso, o projeto foi submetido ao Comitê de Ética em Psicologia e aprovado em 11 de março de 2010, sob o Protocolo de pesquisa $n^{\circ}$ 010.3.2010, segundo as normas vigentes no país para pesquisas envolvendo sujeitos humanos.

\section{Resultados}

\section{Análise da fala das cuidadoras sobre os sistemas de cuidado}

Contemplando o objetivo do presente artigo, a análise do conteúdo das respostas referentes a cada uma das fotos de sistemas de cuidado nas doze categorias permitiu identificar diferenças nas díades de cuidadoras. As médias de evocação de cada categoria ao longo de toda entrevista, comparando mães e suas respectivas duplas de cuidado, estão apresentadas na Tabela 2.

A análise da diferença na fala das díades foi feita através da média de evocação das categorias por meio de testes $t$ bicaudais. Analisando o total de evocação das categorias em toda a entrevista, foram encontradas diferenças significativas nas díades mãe x avó, no que diz respeito ao "Afeto" $(t(18)=-2,17, p<0,05, d=-1,95)$ e ao "Contato Visual" $(t(18)=2,47, p<0,05, d=0,79)$. As avós apresentaram maiores médias na evocação da primeira categoria e as mães da segunda. Diferenças também foram encontradas na comparação entre mães e babás na evocação das categorias "Contato Físico" (t(19) = 3,28, $p<0,05, d=1,70)$, "Comunicação" (t(19) = -2,20, $p<0,05, d=-0,85)$, "Contato Visual" (t(19) =4,09, $p<0,05, d=1,50)$, "Exercício" 
Tabela 2

Média e Desvio-Padrão da evocação das categorias por cuidadoras por tipo de díade (Mães x Avós, Mães x Babás, Mães x Educadoras de Creche). Rio de Janeiro (RJ), 2010

\begin{tabular}{|c|c|c|c|c|c|c|c|c|c|c|c|c|}
\hline \multirow{3}{*}{ Categoria } & \multicolumn{4}{|c|}{ Diades Mãe/Avó } & \multicolumn{4}{|c|}{ Diades Mãe/Babá } & \multicolumn{4}{|c|}{ Diades Mãe/EC } \\
\hline & \multicolumn{2}{|c|}{ Mães } & \multicolumn{2}{|c|}{ Avós } & \multicolumn{2}{|c|}{ Mães } & \multicolumn{2}{|c|}{ Babás } & \multicolumn{2}{|c|}{ Mães } & \multicolumn{2}{|c|}{$E C$} \\
\hline & $M$ & $D P$ & $M$ & $D P$ & $M$ & $D P$ & $M$ & $D P$ & $M$ & $D P$ & $M$ & $D P$ \\
\hline Higiene e saúde & 2,63 & 2,39 & 2,68 & 2,89 & 4,00 & 2,13 & 4,55 & 3,72 & 4,00 & 2,51 & 3,30 & 2,70 \\
\hline Afeto & 2,74 & 1,97 & 4,68 & $4,22^{*}$ & 3,35 & 2,21 & 2,20 & 2,07 & 3,35 & 2,96 & 2,60 & 2,60 \\
\hline Função materna & 0,11 & 0,32 & 0,05 & 0,23 & 0,30 & 0,57 & 0,40 & 0,88 & 1,35 & 3,03 & 0,55 & 0,76 \\
\hline Segurança & 0,89 & 1,37 & 1,79 & 2,25 & 0,70 & 1,03 & 0,60 & 1,10 & 0,75 & 1,41 & 1,25 & 1,48 \\
\hline Brincadeira & 2,42 & 1,77 & 1,42 & 1,80 & 1,30 & 1,30 & 1,85 & 1,73 & 1,55 & 1,43 & 1,15 & 0,81 \\
\hline Contato físico & 3,79 & 3,99 & 2,63 & 3,30 & 3,30 & 2,05 & 1,60 & $1,60^{*}$ & 3,85 & 3,75 & 2,85 & 2,23 \\
\hline Reconhecimento & 0,84 & 1,21 & 0,68 & 1,11 & 0,65 & 1,04 & 0,40 & 0,94 & 0,85 & 1,46 & 0,90 & 1,65 \\
\hline Comunicação & 1,53 & 1,22 & 1,05 & 1,43 & 0,45 & 0,60 & 1,30 & $1,53^{*}$ & 1,25 & 2,12 & 0,85 & 0,93 \\
\hline Contato visual & 1,37 & 1,21 & 2,63 & 3,30 & 1,95 & 1,39 & 1,60 & $1,60^{*}$ & 1,90 & 1,62 & 2,85 & 2,23 \\
\hline Propriocepção & 0,00 & 0,00 & 0,05 & 0,23 & 0,10 & 0,45 & 0,25 & 0,79 & 0,10 & 0,31 & 0,25 & 0,55 \\
\hline Exercício & 1,11 & 1,05 & 1,16 & 1,61 & 1,75 & 1,07 & 0,80 & $0,83^{*}$ & 1,00 & 0,73 & 0,85 & 0,88 \\
\hline Estimulação por objetos & 0,89 & 1,41 & 1,42 & 2,43 & 1,50 & 1,43 & 0,45 & $1,00^{*}$ & 1,55 & 1,85 & 0,55 & 1,05 \\
\hline
\end{tabular}

Nota: ${ }^{*} p<0,05$

EC: Educadoras de Creche; M: Média; DP: Desvio-Padrão.

$(t(19)=3,33, p<0,05, d=0,95)$ e "Estimulação por Objeto" $(t(19)=2,47, p<0,05, d=1,05)$.

Considerando o conteúdo total da entrevista, mães e educadoras de creche parecem ter discursos semelhantes sobre a valorização dos sistemas de cuidado, visto que não apresentaram diferenças significativas na evocação de nenhuma das doze categorias. Mães e avós apresentam algumas diferenças pontuais. As avós falam mais sobre afeto do que as mães, resultado que pode ser interpretado como um sutil indicador de valorização do calor emocional e da relação, característicos de uma socialização para interdependência (Kagitiçibasi, 2007). Por serem mulheres mais velhas, talvez essa valorização esteja ligada a diferenças geracionais.

Mães e babás expressaram diferenças em quase metade das categorias. Seus discursos divergem em importantes pontos: as mães valorizam mais o contato físico e visual do que as babás, provavelmente pela ligação mais próxima que tem com o filho, diferente da babá que desempenha apenas seu papel profissional. Estas, por sua vez, expressam mais a necessidade de comunicação com a criança do que as mães.

Nas seções seguintes são apresentados os resultados da análise da fala das cuidadoras em seus discursos específicos sobre cada um dos sistemas de cuidado parental. O foco está na comparação das cuidadoras de acordo com o tipo de díade e em complementar essas análises gerais.

\section{Díades mãe/avó}

Analisando a fala de mães e avós sobre cada um dos cinco sistemas de cuidado foram encontradas diferenças significativas na evocação das categorias "Brincadeira" e "Contato Visual". Em suas respostas sobre o sistema de "estimulação por objetos", as mães citaram situações de brincadeira com maior frequência que as avós $(t(18)=2,32$, $p<0,05, d=0,95)$. No sistema de trocas "Face-a-face", mães evocaram mais a categoria "Contato Visual" que as avós $(t(18)=2,69, p<0,05, d=0,05)$.

\section{Díades mãe/babá}

A comparação estatística de mães e babás indicou diferenças significativas em três dos cinco sistemas de cuidados parentais. Na fala sobre o sistema contato corporal, as mães evocaram mais que as babás a categoria "Contato Físico" $(t(19)=3$, $p<0,05, d=1)$. Em suas respostas sobre o sistema de estimulação corporal, mães novamente superaram as babás na frequência das categorias "Afeto" 
Tabela 3

Média e Desvio-Padrão da evocação das categorias em cada sistema de cuidado em díades de Mães e Avós. Rio de Janeiro (RJ), 2010

1 de 2

\begin{tabular}{|c|c|c|c|c|}
\hline \multirow{3}{*}{ Categorias } & \multicolumn{4}{|c|}{ Cuidados básicos } \\
\hline & \multicolumn{2}{|c|}{ Mães } & \multicolumn{2}{|c|}{ Avós } \\
\hline & $M$ & $D P$ & $M$ & $D P$ \\
\hline Higiene e saúde & 2,05 & 1,75 & 2,05 & 2,12 \\
\hline Afeto & 0,32 & 0,75 & 0,32 & 0,75 \\
\hline Função materna & 0,05 & 0,23 & 0,05 & 0,23 \\
\hline Segurança & 0,11 & 0,46 & 0,21 & 0,54 \\
\hline Brincadeira & 0,37 & 0,68 & 0,32 & 0,82 \\
\hline Contato físico & 0,37 & 0,76 & 0,32 & 0,58 \\
\hline Reconhecimento & 0,00 & 0,00 & 0,00 & 0,00 \\
\hline Comunicação & 0,21 & 0,54 & 0,11 & 0,46 \\
\hline Contato visual & 0,05 & 0,23 & 0,00 & 0,00 \\
\hline Propriocepção & 0,00 & 0,00 & 0,00 & 0,00 \\
\hline Exercício & 0,05 & 0,23 & 0,00 & 0,00 \\
\hline \multirow[t]{2}{*}{ Estimulação por objetos } & 0,00 & 0,00 & 0,00 & 0,00 \\
\hline & \multicolumn{4}{|c|}{ Contato corporal } \\
\hline Higiene e saúde & 0,05 & 0,23 & 0,11 & 0,32 \\
\hline Afeto & 1,68 & 1,49 & 2,11 & 1,70 \\
\hline Função materna & 0,05 & 0,23 & 0,00 & 0,00 \\
\hline Segurança & 0,37 & 0,60 & 0,68 & 1,25 \\
\hline Brincadeira & 0,05 & 0,23 & 0,05 & 0,23 \\
\hline Contato físico & 1,47 & 1,50 & 1,05 & 1,18 \\
\hline Reconhecimento & 0,16 & 0,50 & 0,21 & 0,54 \\
\hline Comunicação & 0,16 & 0,69 & 0,00 & 0,00 \\
\hline Contato visual & 0,00 & 0,00 & 0,00 & 0,00 \\
\hline Propriocepção & 0,00 & 0,00 & 0,00 & 0,00 \\
\hline Exercício & 0,00 & 0,00 & 0,00 & 0,00 \\
\hline \multirow[t]{2}{*}{ Estimulação por objetos } & 0,00 & 0,00 & 0,00 & 0,00 \\
\hline & \multicolumn{4}{|c|}{ Estimulação corporal } \\
\hline Higiene e saúde & 0,53 & 1,17 & 0,32 & 0,95 \\
\hline Afeto & 0,21 & 0,54 & 0,89 & 1,63 \\
\hline Função materna & 0,00 & 0,00 & 0,00 & 0,00 \\
\hline Segurança & 0,11 & 0,32 & 0,21 & 0,42 \\
\hline Brincadeira & 0,37 & 0,60 & 0,37 & 0,76 \\
\hline Contato físico & 1,32 & 1,92 & 1,00 & 2,43 \\
\hline Reconhecimento & 0,21 & 0,63 & 0,00 & 0,00 \\
\hline Comunicação & 0,05 & 0,23 & 0,00 & 0,00 \\
\hline Contato visual & 0,00 & 0,00 & 0,05 & 0,23 \\
\hline Propriocepção & 0,00 & 0,00 & 0,05 & 0,23 \\
\hline Exercício & 1,00 & 0,94 & 1,16 & 1,61 \\
\hline Estimulação por objetos & 0,05 & 0,23 & 0,00 & 0,00 \\
\hline
\end{tabular}

\begin{tabular}{lcccc}
\hline & \multicolumn{4}{c}{ Estimulação por objetos } \\
\hline Higiene e saúde & 0,00 & 0,00 & 0,05 & 0,23 \\
Afeto & 0,11 & 0,32 & 0,63 & 1,42 \\
Função materna & 0,00 & 0,00 & 0,00 & 0,00 \\
Segurança & 0,11 & 0,32 & 0,26 & 0,65 \\
Brincadeira & 1,58 & 1,43 & 0,63 & $0,83^{*}$ \\
Contato físico & 0,11 & 0,32 & 0,05 & 0,23 \\
Reconhecimento & 0,05 & 0,23 & 0,00 & 0,00 \\
Comunicação & 0,05 & 0,23 & 0,05 & 0,23 \\
Contato visual & 0,05 & 0,23 & 0,00 & 0,00 \\
Propriocepção & 0,00 & 0,00 & 0,00 & 0,00 \\
Exercício & 0,05 & 0,20 & 0,00 & 0,00 \\
Estimulação por objetos & 0,84 & 1,42 & 1,32 & 2,06
\end{tabular}

Tabela 3

Média e Desvio-Padrão da evocação das categorias em cada sistema de cuidado em díades de Mães e Avós. Rio de Janeiro (RJ), 2010

2 de 2

\begin{tabular}{|c|c|c|c|c|}
\hline \multirow{3}{*}{ Categorias } & \multicolumn{4}{|c|}{ Cuidados básicos } \\
\hline & \multicolumn{2}{|c|}{ Mães } & \multicolumn{2}{|c|}{ Avós } \\
\hline & $M$ & $D P$ & $M$ & $D P$ \\
\hline & \multicolumn{4}{|c|}{ Face-a-face } \\
\hline Higiene e saúde & 0,00 & 0,00 & 0,16 & 0,69 \\
\hline Afeto & 0,42 & 0,61 & 0,74 & 1,48 \\
\hline Função materna & 0,05 & 0,23 & 0,00 & 0,00 \\
\hline Segurança & 0,16 & 0,37 & 0,47 & 0,84 \\
\hline Brincadeira & 0,05 & 0,23 & 0,05 & 0,23 \\
\hline Contato físico & 0,53 & 1,02 & 0,21 & 0,42 \\
\hline Reconhecimento & 0,42 & 0,51 & 0,53 & 0,90 \\
\hline Comunicação & 1,05 & 1,03 & 0,89 & 1,37 \\
\hline Contato visual & 1,26 & 1,10 & 0,53 & $0,77^{*}$ \\
\hline Propriocepção & 0,00 & 0,00 & 0,00 & 0,00 \\
\hline Exercício & 0,00 & 0,00 & 0,00 & 0,00 \\
\hline Estimulação por objetos & 0,00 & 0,00 & 0,11 & 0,46 \\
\hline
\end{tabular}

Nota: ${ }^{*} p<0,05$.

M: Média; DP: Desvio-Padrão.

$(t(19)=2,35, p<0,05, d=-0,30)$ e "Exercício" $(t(19)=2,11, p<0,05, d=0,60)$. Para as mães, tanto a estimulação quanto o exercício vêm temperados pelo afeto, indicando maior conteúdo afetivo na fala materna sobre situações de estimulação corporal.

Nas respostas sobre o sistema face-a-face, a categoria "Comunicação" foi mais evocada pelas babás $(t(19)=-2,18, p<0,05, d=-0,60)$ e "Contato Visual" pelas mães $(t(19)=3,79, p<0,05, d=1,30)$. Estas valorizam mais o contato visual com o bebê, atividade característica desse sistema de cuidados. Babás, por sua vez, valorizam mais a comunicação. Observa-se que se em geral a estimulação por objetos não é tão valorizada ao cuidar de seu bebê, são as mães que falam dessas atividades como oportunidades para alguma estimulação e não as babás, talvez só preocupadas com o cuidado em si.

\section{Díades mãe/educadoras de creche}

Mães e educadoras de creche apresentaram diferenças significativas em quatro dos cinco sistemas de cuidado. O de cuidados básicos elicitou em ambas uma alta valorização da "Higiene e Saúde", 
Tabela 4

Média e Desvio-Padrão da evocação das categorias em cada sistema de cuidado em díades de Mães e Babás. Rio de Janeiro (RJ), 2010

1 de 2

\begin{tabular}{|c|c|c|c|c|}
\hline \multirow{3}{*}{ Categorias } & \multicolumn{4}{|c|}{ Cuidados básicos } \\
\hline & \multicolumn{2}{|c|}{ Mães } & \multicolumn{2}{|c|}{ Babás } \\
\hline & $M$ & $D P$ & $M$ & $D P$ \\
\hline Higiene e saúde & 2,65 & 1,46 & 2,40 & 2,16 \\
\hline Afeto & 0,45 & 0,69 & 0,35 & 0,75 \\
\hline Função materna & 0,10 & 0,31 & 0,00 & 0,00 \\
\hline Segurança & 0,00 & 0,00 & 0,00 & 0,00 \\
\hline Brincadeira & 0,15 & 0,37 & 0,05 & 0,22 \\
\hline Contato físico & 0,25 & 0,64 & 0,15 & 0,37 \\
\hline Reconhecimento & 0,00 & 0,00 & 0,00 & 0,00 \\
\hline Comunicação & 0,00 & 0,00 & 0,10 & 0,45 \\
\hline Contato visual & 0,00 & 0,00 & 0,00 & 0,00 \\
\hline Propriocepção & 0,00 & 0,00 & 0,00 & 0,00 \\
\hline Exercício & 0,25 & 0,72 & 0,00 & 0,00 \\
\hline \multirow[t]{2}{*}{ Estimulação por objetos } & 0,30 & 0,66 & 0,00 & 0,00 \\
\hline & \multicolumn{4}{|c|}{ Contato corporal } \\
\hline Higiene e saúde & 0,40 & 0,60 & 0,65 & 1,23 \\
\hline Afeto & 1,50 & 1,28 & 1,20 & 1,11 \\
\hline Função materna & 0,10 & 0,31 & 0,15 & 0,49 \\
\hline Segurança & 0,40 & 0,88 & 0,30 & 0,73 \\
\hline Brincadeira & 0,00 & 0,00 & 0,00 & 0,00 \\
\hline Contato físico & 1,80 & 1,11 & 0,80 & $0,89^{*}$ \\
\hline Reconhecimento & 0,10 & 0,45 & 0,10 & 0,31 \\
\hline Comunicação & 0,00 & 0,00 & 0,05 & 0,22 \\
\hline Contato visual & 0,00 & 0,00 & 0,00 & 0,00 \\
\hline Propriocepção & 0,00 & 0,00 & 0,05 & 0,22 \\
\hline Exercício & 0,05 & 0,22 & 0,00 & 0,00 \\
\hline \multirow[t]{2}{*}{ Estimulação por objetos } & 0,00 & 0,00 & 0,00 & 0,00 \\
\hline & \multicolumn{4}{|c|}{ Estimulação corporal } \\
\hline Higiene e saúde & 0,80 & 1,32 & 1,05 & 1,32 \\
\hline Afeto & 0,40 & 0,50 & 0,10 & $0,45^{*}$ \\
\hline Função materna & 0,00 & 0,00 & 0,05 & 0,22 \\
\hline Segurança & 0,05 & 0,22 & 0,15 & 0,49 \\
\hline Brincadeira & 0,10 & 0,45 & 0,40 & 0,75 \\
\hline Contato físico & 0,80 & 0,89 & 0,35 & 0,67 \\
\hline Reconhecimento & 0,11 & 0,32 & 0,00 & 0,00 \\
\hline Comunicação & 0,05 & 0,22 & 0,00 & 0,00 \\
\hline Contato visual & 0,05 & 0,22 & 0,00 & 0,00 \\
\hline Propriocepção & 0,10 & 0,45 & 0,10 & 0,45 \\
\hline Exercício & 1,40 & 1,05 & 0,80 & $0,83^{*}$ \\
\hline \multirow[t]{2}{*}{ Estimulação por objetos } & 0,25 & 0,79 & 0,00 & 0,00 \\
\hline & \multicolumn{4}{|c|}{ Estimulação por objetos } \\
\hline Higiene e saúde & 0,30 & 1,34 & 0,35 & 1,14 \\
\hline Afeto & 0,25 & 0,55 & 0,15 & 0,49 \\
\hline Função materna & 0,00 & 0,00 & 0,10 & 0,45 \\
\hline Segurança & 0,15 & 0,37 & 0,05 & 0,22 \\
\hline Brincadeira & 1,15 & 1,18 & 1,25 & 1,45 \\
\hline Contato físico & 0,10 & 0,31 & 0,10 & 0,31 \\
\hline Reconhecimento & 0,00 & 0,00 & 0,15 & 0,67 \\
\hline Comunicação & 0,05 & 0,22 & 0,20 & 0,41 \\
\hline Contato visual & 0,05 & 0,22 & 0,00 & 0,00 \\
\hline Propriocepção & 0,00 & 0,00 & 0,10 & 0,45 \\
\hline Exercício & 0,05 & 0,22 & 0,00 & 0,00 \\
\hline Estimulação por objetos & 0,90 & 0,91 & 0,45 & 1,00 \\
\hline
\end{tabular}

Tabela 4

Média e Desvio-Padrão da evocação das categorias em cada sistema de cuidado em díades de Mães e Babás. Rio de Janeiro (RJ), 2010

2 de 2

\begin{tabular}{lccccc}
\hline \multirow{2}{*}{ Categorias } & \multicolumn{4}{c}{ Cuidados básicos } \\
\cline { 2 - 3 } \cline { 6 - 7 } & \multicolumn{3}{c}{ Mães } & & \multicolumn{2}{c}{ Babás } \\
\cline { 2 - 3 } \cline { 6 - 7 } & $M$ & $D P$ & & $M$ & $D P$ \\
\hline Higiene e saúde & 0,15 & 0,37 & & 0,10 & 0,31 \\
Afeto & 0,75 & 1,21 & & 0,40 & 0,60 \\
Função materna & 0,10 & 0,45 & & 0,10 & 0,45 \\
Segurança & 0,10 & 0,31 & & 0,10 & 0,31 \\
Brincadeira & 0,00 & 0,00 & & 0,15 & 0,49 \\
Contato físico & 0,40 & 0,60 & & 0,20 & 0,41 \\
Reconhecimento & 0,45 & 0,94 & & 0,20 & 0,41 \\
Comunicação & 0,40 & 0,75 & & 1,00 & $1,17^{*}$ \\
Contato visual & 1,75 & 1,37 & & 0,45 & $0,94^{*}$ \\
Propriocepção & 0,00 & 0,00 & & 0,00 & 0,00 \\
Exercício & 0,00 & 0,00 & & 0,00 & 0,00 \\
Estimulação por objetos & 0,05 & 0,22 & & 0,00 & 0,00 \\
\hline
\end{tabular}

Nota: ${ }^{*} p<0,05$.

$M$ : Média; $D P$ : Desvio-Padrão.

sendo esta a categoria mais evocada. Nesse sistema, diferenças foram encontradas apenas na evocação do "Afeto", mais valorizado pelas mães $(t(19)=2,13$, $p<0,05, d=0,10)$. A função psicológica dos cuidados básicos é a redução do desconforto, mas, para as mães, pode ser a ocasião de troca de afeto com seu bebê.

Nas respostas sobre o sistema de contato corporal, a categoria "Contato Físico" foi a mais mencionada, convergindo a própria característica definidora do sistema segundo Keller (2007). O "Afeto", o qual também teve alta frequência de evocação no discurso de ambas, também é consistente com a visão e função desse sistema. No entanto, mães e educadoras de creche diferem significativamente na evocação dessa categoria $(t(19)=2,63$, $p<0,05, d=1,20)$ e da "Segurança" (t(19) $=-2,18$, $p<0,05, d=-0,40)$. Mães falam mais do afeto e educadoras falam mais da segurança. É interessante também que as mães falam, novamente, mais de afeto nos cuidados do que as educadoras de creche. Estas, tal como as babás, estariam mais preocupadas em oferecer os cuidados aos bebês atendendo suas necessidades. 
Tabela 5

Média e Desvio-Padrão da evocação das categorias em cada sistema de cuidado em díades de Mães e EC. Rio de Janeiro (RJ), 2010

1 de 2

\begin{tabular}{|c|c|c|c|c|}
\hline \multirow{3}{*}{ Categorias } & \multicolumn{4}{|c|}{ Cuidados básicos } \\
\hline & \multicolumn{2}{|c|}{ Mães } & \multicolumn{2}{|c|}{$\mathrm{EC}$} \\
\hline & $M$ & $D P$ & $M$ & $D P$ \\
\hline Higiene e saúde & 3,20 & 1,85 & 2,50 & 1,67 \\
\hline Afeto & 0,50 & 0,89 & 0,05 & $0,22^{*}$ \\
\hline Função materna & 0,35 & 0,81 & 0,05 & 0,22 \\
\hline Segurança & 0,30 & 0,98 & 0,15 & 0,37 \\
\hline Brincadeira & 0,35 & 0,81 & 0,00 & 0,00 \\
\hline Contato físico & 0,35 & 0,81 & 0,45 & 0,76 \\
\hline Reconhecimento & 0,00 & 0,00 & 0,10 & 0,45 \\
\hline Comunicação & 0,00 & 0,00 & 0,00 & 0,00 \\
\hline Contato visual & 0,05 & 0,22 & 0,05 & 0,22 \\
\hline Propriocepção & 0,00 & 0,00 & 0,00 & 0,00 \\
\hline Exercício & 0,00 & 0,00 & 0,00 & 0,00 \\
\hline \multirow[t]{2}{*}{ Estimulação por objetos } & 0,00 & 0,00 & 0,00 & 0,00 \\
\hline & \multicolumn{4}{|c|}{ Contato corporal } \\
\hline Higiene e saúde & 0,30 & 0,57 & 0,25 & 0,55 \\
\hline Afeto & 1,50 & 1,24 & 1,15 & 1,18 \\
\hline Função materna & 0,20 & 0,52 & 0,10 & 0,31 \\
\hline Segurança & 0,10 & 0,31 & 0,50 & $0,76^{*}$ \\
\hline Brincadeira & 0,10 & 0,31 & 0,00 & 0,00 \\
\hline Contato físico & 2,20 & 2,17 & 1,00 & $1,12^{*}$ \\
\hline Reconhecimento & 0,10 & 0,45 & 0,00 & 0,00 \\
\hline Comunicação & 0,10 & 0,31 & 0,05 & 0,22 \\
\hline Contato visual & 0,00 & 0,00 & 0,00 & 0,00 \\
\hline Propriocepção & 0,00 & 0,00 & 0,00 & 0,00 \\
\hline Exercício & 0,05 & 0,22 & 0,00 & 0,00 \\
\hline \multirow[t]{2}{*}{ Estimulação por objetos } & 0,00 & 0,00 & 0,00 & 0,00 \\
\hline & \multicolumn{4}{|c|}{ Estimulação corporal } \\
\hline Higiene e saúde & 0,30 & 0,73 & 0,40 & 0,99 \\
\hline Afeto & 0,60 & 0,99 & 0,50 & 1,19 \\
\hline Função materna & 0,35 & 1,57 & 0,10 & 0,31 \\
\hline Segurança & 0,05 & 0,22 & 0,00 & 0,00 \\
\hline Brincadeira & 0,10 & 0,31 & 0,05 & 0,22 \\
\hline Contato físico & 1,10 & 1,12 & 1,20 & 1,70 \\
\hline Reconhecimento & 0,05 & 0,22 & 0,05 & 0,22 \\
\hline Comunicação & 0,10 & 0,31 & 0,00 & 0,00 \\
\hline Contato visual & 0,00 & 0,00 & 0,00 & 0,00 \\
\hline Propriocepção & 0,10 & 0,31 & 0,25 & 0,55 \\
\hline Exercício & 0,95 & 0,69 & 0,75 & 0,85 \\
\hline Estimulação por objetos & 0,00 & 0,00 & 0,20 & 0,62 \\
\hline
\end{tabular}

\begin{tabular}{lcccc}
\hline & \multicolumn{4}{c}{ Estimulação por objetos } \\
\hline Higiene e saúde & 0,05 & 0,22 & 0,00 & 0,00 \\
Afeto & 0,15 & 0,49 & 0,20 & 0,52 \\
Função materna & 0,20 & 0,52 & 0,00 & 0,00 \\
Segurança & 0,25 & 1,12 & 0,00 & 0,00 \\
Brincadeira & 0,90 & 1,02 & 1,10 & 0,79 \\
Contato físico & 0,15 & 0,37 & 0,05 & 0,22 \\
Reconhecimento & 0,20 & 0,41 & 0,10 & 0,45 \\
Comunicação & 0,10 & 0,31 & 0,00 & 0,00 \\
Contato visual & 0,15 & 0,49 & 0,00 & 0,00 \\
Propriocepção & 0,00 & 0,00 & 0,00 & 0,00 \\
Exercício & 0,00 & 0,00 & 0,10 & 0,45 \\
Estimulação por objetos & 1,50 & 1,76 & 0,35 & $0,67^{*}$ \\
\hline
\end{tabular}

Tabela 5

Média e Desvio-Padrão da evocação das categorias em cada sistema de cuidado em díades de Mães e EC. Rio de Janeiro (RJ), 2010

2 de 2

\begin{tabular}{lccccc}
\hline \multirow{2}{*}{ Categorias } & \multicolumn{4}{c}{ Cuidados básicos } \\
\cline { 2 - 3 } \cline { 5 - 6 } & \multicolumn{4}{c}{ Mães } & \multicolumn{2}{c}{ EC } \\
\cline { 2 - 3 } \cline { 5 - 6 } & 0,15 & 0,49 & & 0,15 & 0,67 \\
\hline Higiene e saúde & 0,60 & 0,88 & & 0,70 & 1,17 \\
Afeto & 0,25 & 0,64 & & 0,30 & 0,66 \\
Função materna & 0,05 & 0,22 & & 0,60 & 0,94 \\
Segurança & 0,10 & 0,31 & & 0,00 & 0,00 \\
Brincadeira & 0,05 & 0,22 & & 0,15 & 0,49 \\
Contato físico & 0,50 & 0,89 & & 0,65 & 1,18 \\
Reconhecimento & 0,95 & 1,57 & & 0,80 & 0,89 \\
Comunicação & 1,70 & 1,38 & & 1,20 & 1,15 \\
Contato visual & 0,00 & 0,00 & & 0,00 & 0,00 \\
Propriocepção & 0,00 & 0,00 & 0,00 & 0,00 \\
Exercício & 0,05 & 0,22 & 0,00 & 0,00 \\
Estimulação por objetos & & & & & \\
\hline
\end{tabular}

Nota: ${ }^{*} p<0,05$.

M: Média; DP: Desvio-Padrão; EC: Educadoras de Creche.

\section{Discussão}

Os sistemas mais valorizados pelas participantes (mães e outras cuidadoras) foram contato corporal e face-a-face, seguidos de cuidados básicos, estimulação corporal e estimulação por objeto. Os resultados indicaram uma tendência maior das mães em priorizar o sistema de trocas face-a-face. Ressalta-se que nesse sistema o contato ocular mútuo é estimulado, acompanhado pelo uso da linguagem em conversas com o bebê. Estimula, assim, a percepção de agência causal, unicidade e autoeficácia. É um sistema prevalente em contextos onde a autonomia é valorizada, como em sociedades ocidentais urbanas de tendência individualista.

Já o sistema de contato corporal é manifestado na prática de carregar os bebês junto ao corpo do cuidador (nas costas, na frente ou no quadril). Garante proteção contra perigos, apego e regulação corporal. É considerado um sistema de apego filogeneticamente antigo, com a função psicológica de promover uma experiência de segurança, favorecer o desenvolvimento do senso de pertencimento ao grupo, a aceitação de normas e valores transgeracionais e uma vida familiar harmônica e hierárquica. 
As experiências motoras por meio do toque e do movimento de partes do corpo do bebê, em conjunto com reações e modulação comportamental parental, constituem o sistema de estimulação corporal (Keller, 2007). Sua principal função psicológica é o favorecimento da percepção corporal intensificada e da efetividade do corpo como agente sobre os recursos do meio.

Pensando na valorização dos sistemas pelas diferentes cuidadoras, foi possível perceber que todas priorizaram sistemas com tendências tanto voltadas para autonomia (face-a-face) quanto para a relação (contato corporal). Além disso, foi marcante a incidência, em todos os sistemas, da categoria afeto no discurso das diversas entrevistadas. Essas análises serviram para ilustrar que os aspectos afetivos estão presentes no discurso desde etapas iniciais do desenvolvimento. Esse dado pode ser um indicativo bastante característico da cultura brasileira. Esses resultados contribuem para refinar as evidências sobre trajetórias de desenvolvimento em contextos brasileiros. A valorização de autonomia relacionada tem sido predominante (Seidl-de-Moura et al., 2013) e importantes nuances no equilíbrio dessa valorização e da relação têm sido encontradas. Esses estudos brasileiros agora são complementados por dados relativos a outras figuras femininas que cuidam de crianças em um contexto urbano também brasileiro.

Apesar de contribuir para a literatura de cuidados parentais e trajetórias de desenvolvimento, o estudo tem limitações e necessita ser ampliado e aprofundado para melhor compreensão dessas características do contexto cultural em que se desenvolvem as crianças do Brasil. Uma de suas limitações é o pequeno grupo de participantes, apenas do Rio de Janeiro. A exemplo de uma linha de investigações anteriores (Seidl-de-Moura et al., 2013), é necessário realizar pesquisas em demais contextos do país. Além disso, outras ferramentas metodológicas válidas e consistentes, que permitam análises mais sofisticadas, necessitam ser utilizadas em futuros estudos.

\section{Colaboradores}

Todos os autores contribuíram na concepção e desenho do estudo, análise de dados e redação final do artigo.

\section{Referências}

Bakeman, R., Deckner, D. F., \& Quera, V. (2005). Analysis of behavioral streams. In D. M. Teti (Ed.), Handbook of research methods in developmental psychology (pp.394-420). Oxford: Blackwell Publishers.

Bandeira, T. T. A., \& Seidl-de-Moura, M. L. (2012). Crenças de pais e mães sobre investimento parental. Paidéia, 22(53), 355-363.

Cohen, P., \& Bianchi, S. (1999). Marriage, children and women's employment: What do we know? Monthly Labor Review, 122(12), 22-31.

Crosby, D., \& Hawkes, D. (2007). Cross-national research using contemporary birth cohort studies: A look at early maternal employment in the United Kingdom and United States. International Journal of Social Research Methodology, 10(5), 379-404.

Field, A. P. (2009). Discovering statistics using SPSS. London: Sage.

Hansen, K., \& Hawkes, D. (2009). Early childcare and child development. Journal of Social Policy, 38(2), 211-239.

Harkness, S., \& Super, C. M. (1996). Introduction. In S. Harkness \& C. M. Super (Orgs.), Parents' cultural belief systems: Their origins, expressions, and consequences (pp.1-23). New York: The Guilford Press.

Kagitçibasi, Ç. (2007). Family, self, and human development across cultures: Theory and applications. Mahwah: Lawrence Erlbaum Associates.

Kagitçibasi, Ç. (2011). Sociocultural change and integrative syntheses in human development: Autonomous-related self and social-cognitive competence. Child Development Perspectives, 6(1), 5-11.

Keller, H. (2007). Cultures of infancy. London: Lawrence Erlbaum Associates.

Keller, H., \& Chasiotis, A. (2007). Maternal investment. In C. A. Salmon \& T. K. Shackelford (Orgs.), Family relationships: An evolutionary perspective (pp.91-114). New York: Oxford University Press.

Keller, H. (2011). Autonomy and relatedness revisited: Cultural manifestations of universal human needs. Child Development Perspectives, 6(1), 12-18.

Papousek, H., \& Papousek, M. (1991). Ontogeny of social interaction in newborn infants. In C. Euler, $\mathrm{H}$. Forssberg, \& H. Lagercrantz (Orgs.), Neurobiology of 
early infant behavior (pp.217-225). Stockholm: Stockholm Press.

Pinker, S. (2002). O instinto da linguagem. São Paulo: Martins Fontes.

Rapoport, A., \& Piccinini, C. A. (2004). A escolha do cuidado alternativo para o bebê e a criança pequena. Estudos de Psicologia (Natal), 9(3), 497-503.

Rochat, P. (2001). The infant's world. Cambridge: Harvard University Press.

Sear, R., \& Mace, R. (2008). Who keeps children alive? A review of the effects of kin on child survival. Evolution and Human Behavior, 29(1), 1-18.
Seidl-de-Moura, M. L., \& Mendes, D. M. L. F. (2012). Human development: The role of biology and culture. In Seidl-de-Moura, M. L. (Ed.), Human development: Different perspectives (pp.3-19). Croatia: InTech.

Seidl-de-Moura, M. L., Carvalho, R. V. C. C., \& Vieira, M. L. (2013). Brazilian mothers parenting models. In M. L. Seidl-de-Moura (Ed.), Parenting in south american and african contexts. Croatia: InTech.

Recebido: fevereiro 19, 2014

Versão final: julho 16, 2014

Aprovado: setembro 19, 2014 